CRÍTICA, Revista Hispanoamericana de Filosofía

Vol. XXXI, No. 91 (abril 1999): 91-103

\title{
SAVING RELATIVISM FROM ITS SAVIOUR
}

MAX KölBEL

Doctoral Programme in Cognitive Science

Universität Hamburg

In his paper "A Consistent Relativism" (Mind, 106, pp. 33-52), Steven D. Hales proposes a "logic of relativism" (p. 33) with the help of which he wishes to "illuminate the self-refutation charge" (ibid.) against relativism, and which he hopes will "provide a framework in which relativists can consistently promote their... views" (pp. 3334). Hales purports to show that relativism is indeed selfrefuting, according to his treatment of relativism "as a kind of modality" (p. 39). He also proposes a "more modest" and "new-and-improved" (p. 37) relativism, which is not in this way self-refuting, and promotes his logic as a neutral battleground for relativists and absolutists, within which both views are consistent, but neither is logically necessary so that each has to be earned "through honest toil" (p. 38 and p. 39).

Hales adopts the pose of the saviour of relativism, who kindly offers a logic in which a modest relativism is consistent. But within Hales' logic of relativism, the self-refutation objection turns out better than it ever really was. I will to show that (I) the self-refutation argument as first presented and supported by Hales is fallacious, that (II) the semantic principle he later introduces into his logic (in the last paragraph of the appendix) in order to make "principle 
P" and thereby the self-refutation argument valid is precisely the sort of principle that prevents his logic from being a neutral battleground for the debate between absolutists and relativists, and that (III) neither Hales' new-and-improved relativism, nor the unimproved form he rejects, are very plausible readings of relativism. In short: relativism ought to be protected from this self-styled benefactor.

\section{I}

Hales first presents a version of the self-refutation objection according to which relativism, the thesis that everything is (merely) relative, entails that relativism itself is (merely) relative. Therefore, the objection continues, relativism is true according to some perspectives and untrue according to others. According to Hales, "this seems like a paradox, or a contradiction, or something" (p. 34). He then promises to clarify the situation by thinking of relativity in analogy with possibility. The view that everything is possible cannot be right if we accept the S5 principle that everything possibly necessary is necessary. Similarly, it follows from the principle that whatever is relatively absolute is absolute, that relativism is false: if everything is relative then it is also relative that relativism is absolutely false, thus, by the S5 principle's analogue, relativism is absolutely false. ${ }^{1}$

Hales does not give any reason why one should think of relativity in analogy with possibility, or why one should

1 Note that Hales seems to use the words "relative" and "relatively" in two different senses. On one sense, something is relative, or relatively true, just if there is a perspective in which it is true. This is the sense in which he mostly uses the words, and the one he confirms in his definitions of the "relatively"-operator. On the other sense, something is relative, or relatively true, just if there is a perspective in which it is true and there is a perspective in which it is not. I try to avoid confusion by saying "(merely) relative" whenever I believe Hales intends the second sense, or whenever I intend it. 
accept the S5-like principle that what is relatively absolute is absolute ("principle P"). But just as possible and necessary truth can be thought of as, respectively, truth in some and all possible worlds, relative truth can be thought of as truth in some perspective, absolute truth as truth in all perspectives. This does lend the analogy with modality some plausibility, but it does not yet support principle $\mathrm{P}$ - just as the idea alone of accounting for modality in terms of quantification over possible worlds does not yet force one to accept S5.

However, thinking of relative truth as truth according to some perspective, and of absolute truth as truth according to all perspectives is the semantical handle with which Hales wishes "simultaneously to sharpen the standard charge of self-refutation and show that the root intuition behind this charge lies in the acceptance of $\mathrm{P}$ [the S5 principle] (p. 35)".

It is not entirely clear what exactly Hales wants to achieve by the ensuing semantical reconstruction of the self-refutation argument. On the one hand he wishes to sharpen the self-refutation charge. But if his reflections do sharpen the charge, then they presumably rely only on the semantical assumptions, and not on principle P. On the other hand, if he were to succeed in showing that the selfrefutation charge relies essentially on principle $\mathrm{P}$, then his reflections could not sharpen the charge, as the principle is so far unmotivated. The most plausible reading might seem that Hales intends his semantical reflections to vindicate both principle $\mathrm{P}$ and the self-refutation argument. $^{2}$

2 At a later stage, however, Hales seems to imply that the only reason why a relativist ought not to reject principle $\mathrm{P}$ is that this principle explains the "power" of the self-refutation objection, and "honest relativists" (p. 37) need such an explanation. This would seem a bad reason indeed, as rejecting principle $\mathrm{P}$ does not prevent one from using Hales' explanation. The relativist can just say that the self-refutation 
Whatever Hales intends his semantical reconstruction of the self-refutation argument to achieve, I think it is important to show that it does not vindicate the self-refutation argument on semantical grounds. The argument Hales presents is fallacious, as I shall now show.

First, Hales defines relativism as "the claim that every proposition is true in some perspective and untrue in another", and absolutism as the negation of this, namely the view that "there is at least one proposition which has the same truth value in all perspectives" (p. 35). Then he offers a dilemma: if relativism is true, it is either true absolutely, or not absolutely. Suppose the first, i.e. that relativism is absolutely true. Then there is one proposition that has the same truth value in all perspectives, namely the proposition of relativism. Therefore it follows from the supposition that relativism is absolutely true that absolutism is true, i.e. relativism is false. So relativism cannot be absolutely true.

Suppose then, Hales goes on, that relativism is not absolutely, but (merely) relatively true. Then there must be at least one perspective in which relativism is not true, i.e. in which absolutism is true. Now, in such a perspective, in which absolutism is true, at least one proposition must be true absolutely, i.e. on all standards. But this, Hales maintains, is impossible. For

- given the assumption that there are perspectives in which relativism is true - we are guaranteed that the truth value of every proposition will vary across perspectives. Hence, there is no proposition that is true in all perspectives; that is, for every proposition there are perspectives in which it is true and perspectives in which it is untrue. Then relativism

problem has been so powerful because many have mistakenly and unjustifiedly assumed principle P. Moreover, the relativist may have a different explanation. I will offer a different, but not necessarily better explanation in $\S$ III. 
is true in all perspectives, and this... entails that relativism is untrue (p. 36).

The conclusion is, of course, that relativism is absolutely false, as it is neither absolutely true nor (merely) relatively true.

The second part of this argument is fallacious. For "given the assumption that there are perspectives in which relativism is true", we are not "guaranteed that the truth value of every proposition will vary across perspectives". We are merely guaranteed that according to those perspectives in which relativism is true, the truth value of every proposition varies across perspectives.

Let me formalise the argument. First, relativism was defined as the claim that every proposition is true in some perspective and untrue in another:

(R) $\forall p\left[\exists r, s\left[T_{r} p \& \neg T_{s} p\right]\right]$

(Read: for all propositions $p$ : there is a perspective $r$ and there is a perspective $s$, such that $p$ is true relative to $r$ and untrue relative to $s$.)

Absolutism was defined as the negation of relativism:

(A) $\exists p\left[\forall r, s\left[T_{r} p \leftrightarrow T_{s} p\right]\right]$

(Read: there is a proposition $p$, such that for all perspectives $r$ and $s, p$ is true relative to $r$ exactly if it is true relative to $s$.)

The reduction of the first horn of the dilemma goes through: suppose that $(\mathrm{R})$ is true absolutely, i.e. true in all perspectives:

$$
\forall s\left[T_{s}(\mathrm{R})\right]
$$

(Read: for all perspectives $s,(\mathrm{R})$ is true relative to $s$.

Then, by existential generalisation: 


$$
\exists p\left[\forall s\left[T_{s} p\right]\right]
$$

(Read: there is a proposition $p$, such that $p$ is true relative to all perspectives $s$.)

This, however, entails the negation of (R), i.e. (A).

But now consider the second horn, which according to Hales leads us back onto the first. The supposition now is that $(\mathrm{R})$ is not absolutely, but merely relatively true, i.e. true relative to some perspectives, but not relative to others:

$$
\text { (1) } \exists r, s\left[T_{r}(\mathrm{R}) \& \neg T_{s}(\mathrm{R})\right]
$$

(Read: there is a perspective $r$ and there is a perspective $s$, such that $(\mathrm{R})$ is true relative to $r$ and $(\mathrm{R})$ is untrue relative to $s$.)

Hales then detaches the second conjunct:

(2) $\exists s\left[\neg T_{s}(\mathrm{R})\right]$

(Read: there is a perspective $s$, such that $(\mathrm{R})$ is untrue relative to $s$.)

which is equivalent to

(3) $\exists s\left[T_{s}(\mathrm{~A})\right]$

(Read: there is a perspective $s$, such that (A) is true relative to $s$.)

and argues that in such a perspective $s$, in which relativism is not true (i.e. in which absolutism is true), it would have to be true that there is at least one proposition which is true in all perspectives. ${ }^{3}$ In other words, he wishes to replace

3 Strictly, Hales should say that the truth of absolutism in $s$ requires that some proposition has the same truth value in all perspectives (according to $s$ ). But this difference does not matter given the fact that the negation of a proposition untrue in all perspectives is true in all perspectives. 
"(A)" in (3) by the full definition of absolutism. The result is:

(4) $\exists r\left[T_{r}\left(\exists p\left[\forall s, t\left[T_{s} p \leftrightarrow T_{t} p\right]\right]\right)\right]$

(Read: there is a perspective $r$, such that the following claim is true relative to $r$ : there is a proposition $p$, such that for any perspectives $s$ and $t, p$ is true relative to $t$ just if it is true relative to $s$.)

Thus, according to at least one perspective, it is true that there is at least one proposition which has the same truth value in all perspectives. Hales takes this to conflict with the assumption (1), because detaching the first conjunct it follows from (1) that there is at least one perspective in which relativism is true:

(5) $\exists s\left[T_{s}(\mathrm{R})\right]$

(Read: there is a perspective $s$, such that $(\mathrm{R})$ is true relative to $s$.)

and from this he takes it to follow that "the truth value of every proposition will vary across perspectives" (p. 36). This is just what $(\mathrm{R})$ says. But $(\mathrm{R})$ is not in conflict with (4) (nor does (R) follow from (5)). According to (4), (R) is in conflict with at least one perspective, because there is one in which the negation of (R), (A), is true. But (4) and (R) are not themselves in conflict. It does follow from (5) that there is a perspective in which it is true that "the truth value of every proposition will vary across perspectives" (p. 36):

(6) $\exists r\left[T_{r}\left(\forall p\left[\exists s, t\left[T_{s} p \& \neg T_{t} p\right]\right]\right)\right]$

(Read: there is a perspective $r$, such that it is true relative to $r$ that: for every proposition $p$, there are perspectives $s$ and $r$, such that $p$ is untrue relative to $r$ and true relative to $s$.) 
But (6) does not entail that relativism is true in all perspectives, i.e. is absolutely true.

Hales' unjustified assumption underlying his reconstruction of the self-refutation charge is presumably that if a proposition quantifying over perspectives is true according to some perspective, then it is true according to all perspectives. The analogous assumption might be motivated in a possible world semantics for logical modality: what is logically possible/necessary at one world is also logically possible/necessary at any other world. But with other forms of modality, the assumption cannot be taken for granted. In order to model different kinds of modality, one can introduce an "accessibility" relation between worlds, and make the evaluation of modal propositions at a world depend on which other worlds are accessible from that world. Thus, it will be true at a world $w$ that possibly $p$, iff there is a world $w^{\prime}$, which is accessible from $w$, at which $p$ holds. Now, if the accessibility relation is symmetrical and transitive, i.e. an equivalence relation, then (the analogue of) the assumption underlying Hales' reconstruction holds: modal claims are evaluated with respect to the same domain of worlds at all worlds. In particular, the S5 principle that everything possibly necessary is also necessary holds: if it is true at a world $w$ that possibly necessarily $p$, then there is a world $w^{\prime}$, at which it is true that necessarily $p$. From this it follows that $p$ is true at all worlds accessible from $w^{\prime}$. But as the same worlds are accessible from $w, p$ is also necessarily true at $w$.

In his formal appendix, Hales provides a semantics for the operators ("is true in some perspectives") and [ ] ("is true in all perspectives") in the language RL, a semantics analogous in all detail to the modal semantics just 
described. A "commensurability" relation takes the role of the accessibility relation. Now, in the last paragraph of his appendix, Hales rightly points out that principle $\mathrm{P}$ is a theorem of RL if the commensurability relation is symmetrical and transitive.

However, there is no reason to assume that the commensurability relation invoked in Hales' language RL is an equivalence relation. Hales himself says earlier that "there is no deep fact about commensurability. The relation is invented to service the needs of the logic (p. 42, emphasis in original)".

In other words, if a relativist doesn't want to accept principle P (nor Hales' self-refutation argument), he will invent a commensurability relation that is not symmetrical and transitive. And Hales, too, ought to opt for a non-symmetrical or non-transitive commensurability relation. For he says that

It is a benefit of the analysis of relativism offered here that absolutists can accept the formal system as well as relativists. That way, all disputants can quit arguing about the selfrefutation problem, or talking past each other, and consider reasons for and against strong relativist claims on equal footing (p. 38).

If it is assumed from the outset, that the commensurability relation is such that principle $\mathrm{P}$ holds, then surely relativists cannot accept the formal system, as their view would be false by logic in such a system. Moreover, if they do not assume the symmetry and transitivity of the relation, the disputants can equally quit arguing about the self-refutation objection: because it is fallacious, as we have seen in $\S$ I. Hales seems to require in addition, that the "power" (p. 37) of the self-refutation problem be explained. I have already pointed out that Hales' own explanation, 
which makes principle $\mathrm{P}$ responsible, does not depend on the validity of that principle: many people thought that relativism was self-refuting because they assumed principle P. ${ }^{4}$ Whether or not that principle is valid is a different question.

\section{III}

According to Hales, relativism is the view that "everything is [merely] relative", which he interprets as meaning that every proposition is true in some perspectives and untrue in others. As he thinks that this form of relativism is inconsistent, he proposes a different, "new-and-improved" version of relativism: the view that "whatever is true is relatively true" (p. 37). I believe that both versions can be improved upon.

While the first version is not inconsistent in the way Hales thinks, it perhaps goes too far. It entails for example, that there are logically inconsistent perspectives, namely perspectives in which contradictions are true and tautologies false. Who would be interested in such perspectives? On the other hand, it might be considered technically convenient to assume that all perspectives are logically consistent. ${ }^{5}$ Hales' new-and-improved relativism, however, does not seem to deserve the name "relativism" at all. The strictest absolutist could hold that for every $p$, if $p$ is true, then there is a perspective in which $p$ is true. Hales is happy

4 The explanation for "the power of the self-refutation problem, that Hales demands can only be an explanation for the influence the problem has had. He cannot demand that the relativist explain why relativism is self-refutating, as that would beg the question.

5 Hales himself seems to be assuming the consistency of perspectives, when he infers from the assumption that relativism is untrue in a given perspective $p$ that "not-relativism - that is, absolutismis true" (p. 36) in that perspective. See also my formalisation of this inference on p. 6 above, i.e. the inference from (2) to (3). 
to admit this, and makes the suggestion that the relativist ought "to argue that most truths are merely relatively true" (p. 38). So not even Hales himself believes in his new-andimproved version.

What then could relativism be? I propose to think of relativism about truth in analogy with other, less controversial relativity theses. Einstein, for example, was a relativist about simultaneity, for he held that whether two events are simultaneous is relative to a frame of reference. Many logicians are relativists about formal validity, because they hold that whether an argument is formally valid is relative to a choice of logical constants. What do these views have in common? They are all views that it is not determined whether a certain predicate applies to a given object, or $n$-tuple of objects, without fixing an additional parameter that can be fixed in several different ways. Given a certain frame of reference, it is determined which events are simultaneous. Given a choice of logical constants, it is determined which arguments are formally valid.

But the mere acceptance of a new parameter is not sufficient for being a relativist. If Einstein had thought that there was only one correct frame of reference, he wouldn't have been a relativist about simultaneity. When a logician thinks that there is only one correct set of logical constants, then he is not yet a relativist about formal validity. For if a would-be relativist believed that there is only one correct way of fixing the additional parameter, then why should he insist on introducing the additional parameter? Einstein was a relativist about simultaneity, precisely because he denied that only one frame of reference is correct or relevant. Relativists about validity are so-called, because they deny that only one set of constants is correct or interesting. In general, therefore, a relativist needs not only to introduce an additional parameter which can be fixed in several dif- 
ferent ways, but he must also deny that only one of these ways is correct.

My proposal is therefore that a relativist about truth is someone who not only introduces the additional parameter of perspective (like Hales' new-and-improved relativist), but also denies that only one perspective is correct. An absolutist, on this view, might well (perhaps for the sake of arguing with the relativist) accept the perspectival parameter, but he will maintain that only one perspective is correct.

If this is how we have to understand relativism about truth, then the "power" of the self-refutation charge can be explained in a different way. ${ }^{6}$ According to the "pragmatic" version of the self-refutation argument, the communicative function of assertion is conveying information. An assertoric utterance therefore functions properly, when its content is, as a result of the utterer's efforts, true, and the audience comes to believe what has been asserted to be true. Now, if truth were relative, and there was no one correct perspective, then how would the audience know what to come to believe? A serious assertion therefore presupposes that what is asserted can be true absolutely. Thus, if the relativist seriously asserts his thesis, he presupposes its falsity. Asserting relativism is like saying "I can't say anything.", it is pragmatically self-refuting.

This version of the self-refutation charge, I believe, makes it a serious objection. The relativist's reply will be that seriously asserting something doesn't presuppose absolutism. While the proper function of assertion might be

6 I am not claiming that this different explanation of the power of the self-refutation charge is a better explanation. The fact that Hales presents his - as we have seen fallacious - argument so convincingly is evidence for the adequacy of his explanation at least in some cases. Passmore 1961 and Mackie 1964 are evidence that the "pragmatic" version of the self-refutation argument has also had its influence. 
the transmission of information, such a transmission can be achieved without the presupposition of absolutism. All the audience needs is reason to believe that the speaker's perspective at the time of utterance is relevantly similar to their own, namely with respect to the proposition asserted.

This and other objections to relativism in my sense, however, will remain to be discussed on another occasion.

\section{REFERENCES}

Hales, Steven D., 1997, “A Consistent Relativism”, Mind, 106, pp. 33-52.

Mackie, John L., 1964, "Self-Refutation -A Formal Analysis", Philosophical Quarterly, 14, pp. 193-203.

Passmore, John, 1961, Philosophical Reasoning, Duckworth, London. 